\title{
ORMDL3 is associated with airway remodeling in asthma via the ERK/MMP-9 pathway
}

\author{
FEI YU ${ }^{1,2^{*}}$, YAN SUN $^{1 *}$, JIACHEN YU $^{3}$, ZHEN DING $^{2}$, JINRONG WANG $^{1}$, \\ LANYUN ZHANG $^{2}$, TIEJING ZHANG ${ }^{2}$, YUN BAI $^{4}$ and YULIN WANG ${ }^{1}$ \\ ${ }^{1}$ Department of Pediatrics, Shandong Provincial Hospital Affiliated to Shandong University, \\ Jinan, Shandong 250021; ${ }^{2}$ Department of Pediatrics, Traditional Chinese Hospital of Zibo, Zibo, \\ Shandong 255300; ${ }^{3}$ School of Medicine, Shandong University, Jinan, Shandong 250012; ${ }^{4}$ Department of \\ Pediatrics, Jilin Academy of Traditional Chinese Medicine, Changchun, Jilin 132000, P.R. China
}

Received December 4, 2015; Accepted January 4, 2017

DOI: $10.3892 / \mathrm{mmr} .2017 .6413$

\begin{abstract}
ORMDL sphingolipid biosynthesis regulator 3 (ORMDL3) has been previously implicated in asthma pathogenesis, its effect on airway remodeling remains to be elucidated. The present study examined the expression levels of ORMDL3 in a mouse model of asthma. Mice were divided into three groups: Asthmatic model $(n=10)$, budesonide-treated $(n=10)$ and a control group $(n=8)$. Asthma was induced by sensitization with ovalbumin (OVA) and aluminum hydroxide on day 1, 7 and 14. Subsequently mice were exposed to OVA three times per week from day 28. In order to investigate the mechanism of airway remodeling $100 \mu \mathrm{g} / \mathrm{kg}$ aerosol budesonide was administered to 6 animals prior to exposure to OVA. The condition of lung tissues was assessed through histology, and the expression levels of ORMDL3, phosphorylated-extracellular-signal regulated kinase (p-ERK) and matrix metallopeptidase-9 (MMP-9) were quantified using immunohistochemistry, reverse transcription-quantitative polymerase chain reaction and western blotting. A severe inflammatory response and airway remodeling were pretreatment with budesonide. Expression levels of ORMDL3, phosphorylated (p)-ERK and MMP-9 were significantly greater in the asthma-model group; however, in the group pretreated with budesonide their expression was reduced. Expression levels of ORMDL3, p-ERK and MMP-9 were significantly positively correlated with bronchial wall thickness. ORMDL3 expression was significantly positively correlated with p-ERK and MMP-9. Therefore, increased ORMDL3 expression may
\end{abstract}

Correspondence to: Dr Yulin Wang, Department of Pediatrics, Shandong Provincial Hospital Affiliated to Shandong University, 324 Jingwuweiqi Road, Jinan, Shandong 250021, P.R. China

E-mail: liyongyufei@163.com

*Contributed equally

Key words: RMDL3, airway remodeling, MMP-9, ERK, asthma induce the p-ERK/MMP-9 pathway to promote pathological airway remodeling in patients with asthma.

\section{Introduction}

Asthma is characterized by airway inflammation, bronchial hyper-responsiveness and airway remodeling. Airway remodeling entails a wide array of pathophysiological events, including epithelial damage, mucus gland and goblet cell hyperplasia, subepithelial fibrosis, smooth muscle hypertrophy and hyperplasia, vascular changes and disturbances in the homeostasis of the extracellular matrix (ECM) (1). These factors contribute to persistent bronchial hyper-responsiveness and airway remodeling and may negatively impact pulmonary function (1). However, despite extensive previous studies aiming to elucidate the pathological processes responsible for airway remodeling, few therapeutic strategies have proved to be effective in reversing the remodeling (1-3). Therefore, novel therapeutic strategies targeting airway remodeling are required.

Genetic and environmental factors may influence development and clinical presentation of asthma and airway remodeling. Previous genome-wide association studies reported that the orosomucoid-like 3 (ORMDL3) gene was strongly associated with development asthma and recurrent wheezing (3-5). However, the biological role of ORMDL3 in asthma remains to be elucidated. In 2007 the role of ORMDL3 in asthma development was confirmed and abnormal expression of ORMDL3 was detected in over a third of asthmatic children under the age of 7 years (6). In particular, the rs7216389 site was closely correlated with childhood asthma susceptibility.

As in human asthma patients, ORMDL3 gene expression in bronchial epithelial cells was identified to be substantially elevated in wild-type mice exposed to allergens (by 127-fold) (7). Additionally, ORMDL3 expression was induced by allergen and cytokine [interleukin (IL)-4 and IL-13] stimulation and was reported to promote matrix metalloproteinase-9 (MMP-9) expression in asthmatic mice (2,8-10). MMPs are proteolytic enzymes that degrade ECM components under physiological conditions and during pathological processes (3). 
Upregulation or inappropriate secretion of MMP-9 by structural or inflammatory cells has been reported to contribute to the pathophysiology of asthma, particularly airway remodeling (11). Activation of the ROS proto-oncogene 1, receptor tyrosine kinase (ROS)-extracellular signal-regulated kinase (ERK)-MMP-9 signaling pathway was also reported to induce cell migration, proliferation and extracellular matrix collagen synthesis (12-14). Monocyte migration was associated with MMP-9 activity; however, the activation of ERK1/2 signaling pathways and overexpression of ORMDL3 in eosinophils was reported to increase ERK1/2 phosphorylation in vivo (11). The present study used a mouse model of asthma to determine the role of ORMDL3 in asthmatic airway remodeling and investigate the potential association between ORMDL3 and ROS-ERK-MMP-9 signaling pathway in this process.

\section{Materials and methods}

Animals. BALB/c female mice, 8 -weeks old weighing $20 \pm 2 \mathrm{~g}$ were purchased from the Experimental Animal Center of Shandong University Medical College (Jinan, China). The mice were housed in a specific pathogen-free animal facility at the animal center. All animals were reared under relative conditions at 20 to $26^{\circ} \mathrm{C}$, a humidity of 60 to $70 \%$ (cage pressure difference between inside and outside, $+15 \mathrm{~Pa}$; ventilation speed, 55 times/h) and were housed in a room with a $12 \mathrm{~h}$ light/dark cycle. In addition, the animals had access to chow and water ad libitum. All experimental procedures described in this work were performed in accordance with the guidance suggestions for the care and use of laboratory animals, formulated by the Animal Ethics Committee of Shandong Medical University.

Mouse model of asthma. A total of 28 mice were maintained in the absence of environmental pathogens for 1 week prior to the experiments in the present study. They were divided into three groups: i) An asthmatic model group $(n=10)$; ii) budesonide-treated group $(n=10)$; and iii) control group $(n=8)$. The mice in the asthmatic and budesonide treatment groups were sensitized with $100 \mu$ g ovalbumin (OVA; grade V; Sigma-Aldrich; Merck KGaA, Darmstadt, Germany) and 4 mg aluminum hydroxide (Sigma-Aldrich; Merck KGaA) emulsified in phosphate-buffered saline (PBS) on days 1, 7 and 14, then exposed to $1 \%$ OVA 3 times a week for $30 \mathrm{~min}$ from day 28. Mice in the budesonide treatment group were exposed to aerosol budesonide $(100 \mu \mathrm{g} / \mathrm{kg}$ ) 3 times per week for $30 \mathrm{~min}$ from day 21. Mice in the control group were sensitized and challenged with PBS instead. Aerosol budesonide was generated using a Germany Berry nebulizer (Inqua Neb PLUS). Following 6 weeks, the mice were anesthetized by intraperitoneal injection with $1 \%$ pentobarbital sodium $(50 \mathrm{mg} / \mathrm{kg}$; Wuhan Yitai Technology Co., Ltd., Wuhan, Hubei, China) and then sacrificed to collect the lung tissues samples. The mouse asthma model was established as previously described (8).

Hematoxylin and eosin staining. The lungs were harvested and tissue sections were prepared as previously described (15). Standard hematoxylin and eosin staining techniques were applied, and each specimen with a complete tracheal cross was observed via microscope (DM4000B; Leica Microsystems,
Inc., Buffalo Grove, IL, USA), and Leica IM 50 Image Manager software (DM4000B; Leica Microsystems, Inc.) was used to measure the bronchial wall inner perimeter $(\mathrm{Pi})$, bronchial wall peripheral area (Wat1), the bronchial wall area (Wat2). The total bronchial wall area (Wat) and bronchial wall thickness were calculated as follows: Wat=Wat1+Wat2; bronchial wall thickness $=$ Wat $/ \mathrm{Pi}$. These measurements were used to evaluate airway remodeling (10).

Masson staining. Masson staining was performed as previously described (15). To estimate the extent of collagen fiber deposition, staining was categorized into four levels: i) Level 0 , no collagen or only a small quantity of filamentous collagen; ii) level 1, few slender and fasciculate collagen fibers; iii) level 2, collagen fiber fusion into a thin strip; and iv) level 3 , broad collagen fibers or collagen fibers molded into small flakes. A total of 5 high-powered fields of each specimen were reviewed and the indices of collagen deposition in the 3 groups were calculated.

Immunohistochemistry. Expression levels of ORMDL3, MMP-9 and ERK in the formalin-fixed, paraffin-embedded lung tissue sections were assessed by immunohistochemical staining. Samples were incubated with antibodies specific to ORMDL3 (dilution, 1:200; cat. no. ab107639; Abcam, Cambridge, UK), ERK (dilution, 1:200; cat. no. 9102; Cell Signaling Technology, Inc., Danvers, MA, USA), phosphorylated (p)-ERK (dilution, 1:200; cat. no. 9103; Cell Signaling Technology, Inc.) and MMP-9 (dilution, 1:200; cat. no. AB19016; Merck KGaA) overnight, at $4^{\circ} \mathrm{C}$, then staining was detected with biotinylated secondary antibodies (goat anti-rabbit horseradish peroxidase-IgG secondary antibodies; dilution, 1:2,000; cat. no. SP-9001; Beijing Zhongshan Jinqiao Biotechnology Co., Ltd., Beijing, China) and DAB reagent (Beijing Zhongshan Jinqiao Biotechnology Co., Ltd.) at $37^{\circ} \mathrm{C}$ in the incubator for $30 \mathrm{~min}$. A total of 10 fields of each specimen were reviewed, in 10 random visual fields, and staining was assessed using ImageJ software v.10.2 (https://imagej.nih. gov/ij/).

Reverse transcription-quantitative polymerase chain reaction $(R T-q P C R)$. Total RNA was extracted from lung tissues using TRIzol reagent (Invitrogen; Thermo Fisher Scientific, Inc., Waltham, MA, USA). mRNA was transcribed into cDNA using the PrimeScript RT Master Mix Perfect Real-Time kit (Takara Biotechnology Co., Ltd., Dalian, China). qPCR was performed with the Step One Plus Real-Time PCR system (Biosystems 7500; Takara Biotechnology Co., Ltd.), using cDNA and SYBR-Green (Takara Biotechnology Co., Ltd.). Expression levels of ORMDL3 and MMP-9 were normalized to GAPDH. The primers for qPCR were as follows: ORMDL3, sense 5'-GGGGGTGGTCAGGAAAGAGGCT-3', antisense 5'-GGGTTGCCAGGAAGCCCACAAA-3'; GAP DH, sense 5'-CCAGGTGGTCTCCTCTGACTT-3', antisense 5'-GTTGCTCGTAGCCAAATTCGTTGT-3'; and MMP-9 sense 5'-CCTCTGGAGGTCGACGTGA-3'; antisense 5'-TAGGCTTTCTCTCGGTACTGGAA-3'. PCR amplification conditions were as follows: initial denaturation $95^{\circ} \mathrm{C}$ for $10 \mathrm{~min}$, followed by $95^{\circ} \mathrm{C}$ for $30 \mathrm{sec}$ and $60^{\circ} \mathrm{C}$ for $1 \mathrm{~min}$, for a total of 40 cycles. 
Western blotting. Lung tissue protein content was assessed using a Bio-Rad protein assay (Bio-Rad Laboratories, Inc., Hercules, CA, USA) to which proteinase inhibitors were added. Subsequently, 4xSDS sample buffer was added and $40 \mu \mathrm{g}$ protein was loaded on to a $15 \%$ SDS-PAGE, which was probed with primary antibodies against ORMDL3 (dilution, 1:500; cat. no. ab107639; Abcam), ERK (dilution, 1:500; cat. no. 9102; Cell Signaling Technology, Inc.), p-ERK (dilution, 1:500; cat. no. 9106; Cell Signaling Technology, Inc.), MMP-9 (dilution, 1:500; cat. no. AB19016; Merck KGaA) and $\beta$-actin (dilution, 1:2,000; dilution, 1:5,000; cat. no. SC-130300; Santa Cruz Biotechnology, Inc., Dallas, TX, USA) at $4^{\circ} \mathrm{C}$ on a shaker for1 $2 \mathrm{~h}$. It was then probed with the secondary antibody, goat anti rabbit horseradish peroxidase-IgG (dilution, 1:5,000; cat. no. ZB230; Beijing Zhongshan Jinqiao Biotechnology Co., Ltd.), at $24^{\circ} \mathrm{C}$ for $1 \mathrm{~h}$. The scanned intensities were quantified using an electrochemiluminescence kit (cat. no. WBKLS0050; EMD Millipore, Billerica, MA, USA) and scanning the gels using the Step One Software v2.1 (Bio-Rad Laboratories, Inc.). The band intensity was analyzed by Image J software v 10.2 (https://imagej.nih.gov/ij/). Relative absorbance values of each target protein were normalized relative to $\beta$-actin expression and experiments were repeated in triplicate.

Statistical analysis. Statistical analysis was performed using SPSS version 20.0 (IBM SPSS, Armonk, NY, USA). Data are presented as the mean \pm standard deviation. Multiple groups were compared using one-way analysis of variance and the Kruskal-Wallis test. Pearson correlation analysis was used to analyze the correlation between various factors. $\mathrm{P}<0.05$ was considered to indicate a statistically significant difference.

\section{Results}

Asthma mouse model. A mouse model of asthma was established as previously described (8). Briefly, animals were pre-sensitized with OVA and aluminum hydroxide, then exposed to OVA 3 times per week for 6 weeks. To investigate the capacity of budesonide to modify airway inflammation some mice were treated with aerosol budesonide. After 6 weeks, the mice were euthanized and the lungs were collected to assess airway inflammation and damage.

Airway inflammation. In the asthmatic model group, tracheal epithelial cells were shed, the small airway layer was doubled, smooth muscle layer was thickened and a large number of lymphocytes and macrophages had infiltrated the bronchoalveolar walls (Fig. 1A-C). Airway structures in the lungs of healthy control mice were intact and there were no signs of epithelial cell proliferation, tube wall edema or inflammatory cell infiltration. As indicated in Fig. 1D, bronchial hyperplasia and airway wall thickness was significantly increased in the model group compared with the control group (19.9 \pm 0.4 vs. $12.1 \pm 0.2 \mu \mathrm{m} ; \mathrm{P}<0.01)$. In the budesonide-treated group bronchial hyperplasia and airway wall thickness was significantly reduced compared with the model groups $(15.1 \pm 0.3$ vs. $19.9 \pm 0.4 \mu \mathrm{m} ; \mathrm{P}<0.01)$. However, budesonide treatment did not entirely ameliorate asthma-induced airway wall thickening to the same level as the control group $(15.1 \pm 0.3$ vs. $12.1 \pm 0.2 \mu \mathrm{m} ; \mathrm{P}<0.05 ; \mathrm{P}=0.011$; Fig. 1D); however, infiltration of inflammatory cells and damage to airway structures was substantially alleviated following administration of budesonide (Fig. 1).

Airway remodeling. The airway walls were thin and mucosal structures were intact, without obvious proliferation of smooth muscle hyperplasia or collagen deposition in the control group. In the asthmatic model group, the airway walls were thickened compared with the control group and smooth muscle hyperplasia and hypertrophy were observed. Large deposits of collagen surrounded the vessels and alveolar interstitium, and the collagen-staining index was significantly higher compared with the control group $(3.50 \pm 0.21$ and $0.8 \pm 0.24 ; \mathrm{P}<0.01)$. Following budesonide treatment, the tracheal wall hyperplasia was reduced and the collagen-deposition index was significantly reduced compared with the asthmatic model group $(1.90 \pm 0.23$ and $3.50 \pm 0.21 ; \mathrm{P}<0.01)$; however, it was still higher than the control group $(1.90 \pm 0.23$ and $0.8 \pm 0.24$, respectively; $\mathrm{P}<0.01$; Fig. 2).

ORMDL3 expression level. ORMDL3 expression level in lung tissues was detected by immunohistochemical staining. ORMDL 3 was primarily located in the nucleus and cytoplasm of inflammatory and epithelial cells, as indicated in Fig. 3A-C. The level of ORMDL3 immunohistochemical staining was quantified using ImageJ (Fig. 3D). ORMDL3 expression level was low in the control group; however, ORMDL3 expression increased in asthmatic mice $(67.98 \pm 9.85$ and $26.08 \pm 12.18 \%$; $\mathrm{P}<0.05, \mathrm{P}=0.026)$. Compared with the asthmatic model group, administration of budesonide significantly reduced ORMDL3 expression (67.98 \pm 9.85 and $57.56 \pm 7.57 \% ; \mathrm{P}<0.05, \mathrm{P}=0.021)$; however, the treatment did not entirely reduce the level of ORMDL3 expression to healthy control levels $(57.56 \pm 7.57$ and $26.08 \pm 12.18 \%$; $\mathrm{P}<0.01$; Fig 3D). Western blotting confirmed these observations (Fig. 3E), and to further confirm these results, the level of ORMDL3 mRNA in lung tissues was assessed by RT-PCR (Fig. 3F). The ORMDL3 mRNA level in the lung tissues of asthmatic model mice was significantly elevated when compared with healthy control mice $(\mathrm{P}<0.01)$ and administration of budesonide to asthmatic mice significantly reduced the mRNA expression of ORMDL3 $(\mathrm{P}<0.01)$, however, not to healthy control levels $(\mathrm{P}<0.01)$. Upregulation of ORMDL3 protein was significantly positively correlated with bronchial wall thickness ( $r=0.968, P<0.01$; Fig. $3 G)$. As bronchial wall thickening is a characteristic feature of asthma airway remodeling, these data indicated that ORMDL3 may serve a key role in airway remodeling.

MMP-9 expression level. MMP-9 expression level of lung tissues was detected by immunohistochemical staining. MMP-9 was primarily located in the nucleus and cytoplasm of epithelial cells, as indicated in Fig. 4A-C. The level of MMP-9 immunohistochemical staining was quantified using ImageJ software. Low levels of MMP-9 expression were detected in the control group; however, MMP-9 expression was greater in asthmatic mice $(85 \pm 13.57$ and $20.28 \pm 7.33 \%$, $P<0.01$; Fig. 4D). Administration of budesonide significantly reduced MMP-9 expression level $(85 \pm 13.57$ and $64.07 \pm 9.53 \%, \mathrm{P}<0.01$; Fig. 4D); however, did not reduce the level of MMP-9 expression to healthy control levels $(64.07 \pm 9.53$ and $20.28 \pm 7.33 \%, \mathrm{P}<0.05$; 
A

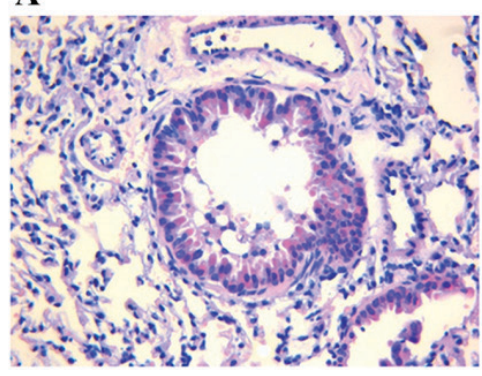

B

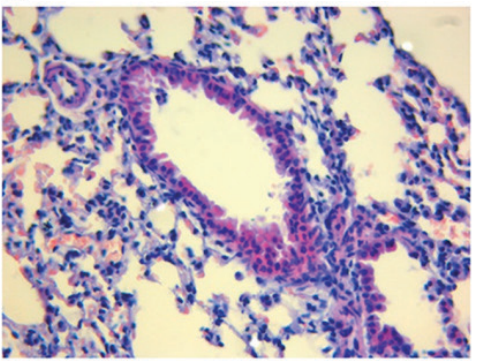

C

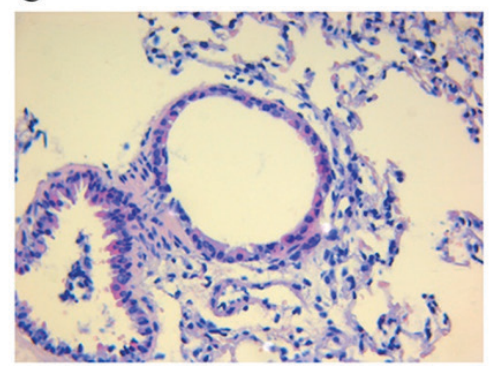

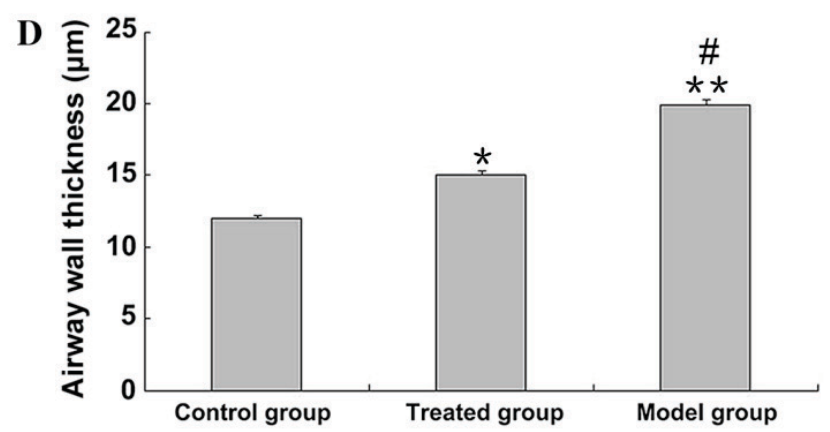

Figure 1. Bronchial hyperplasia in lung tissue was observed using hematoxylin and eosin staining. (A) Tracheal structures were damaged and inflammatory cell infiltration was observed in the asthmatic group. (B) Tracheal structural damage and inflammatory cell infiltration was alleviated in the budesonide-treated group. (C) Tracheal structures were not compromised and inflammatory cell infiltration was not observed in the healthy control group. Magnification, $\mathrm{x} 100$. (D) Quantification of airway wall thickness. ${ }^{*} \mathrm{P}<0.05$ and ${ }^{* *} \mathrm{P}<0.01$ vs. control group; ${ }^{*} \mathrm{P}<0.05$ vs. treated group.

A

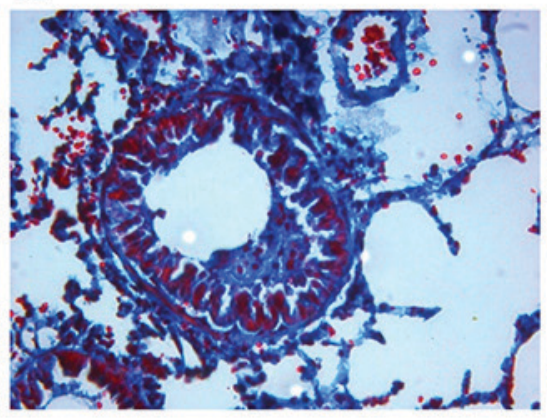

B

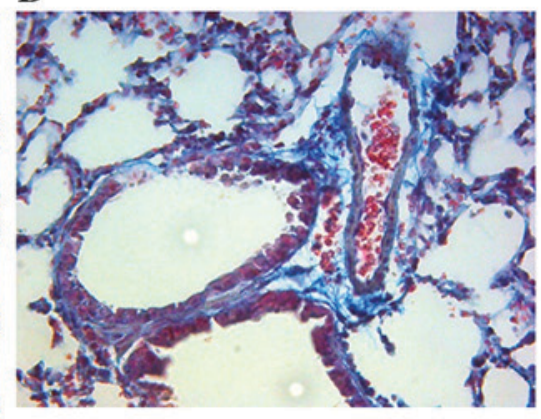

C

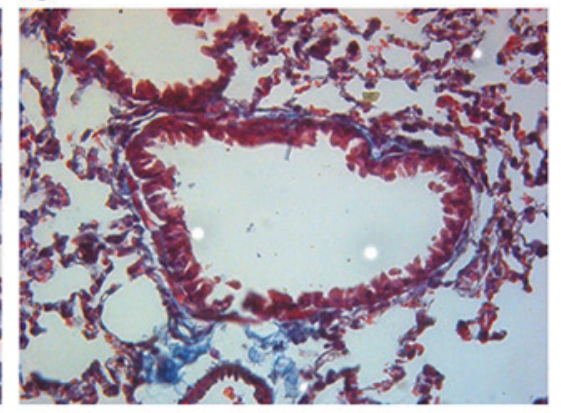

Figure 2. Increased collagen deposition in lung tissue was determined using Masson staining. (A) Substantial collagen deposition was observed in the interstitium of the asthmatic group. (B) Collagen deposition was reduced in the budesonide-treated group when compared with the asthmatic group. (C) Small quantity of collagen deposition in pulmonary interstitial was observed in the healthy control group. Magnification, x100.

$\mathrm{P}=0.013$ Fig 4D). Western blotting confirmed these observations (Fig. 4E). Additionally, the mRNA MMP-9 level in lung tissues was assessed by RT-qPCR (Fig. 4F). MMP-9 mRNA level in the lung tissues of asthmatic model mice was significantly increased compared with healthy control mice $(\mathrm{P}<0.01$; Fig. 4F) and treatment with budesonide of asthmatic mice significantly reduced the mRNA expression of MMP-9 $(\mathrm{P}<0.05 ; \mathrm{P}=0.011)$; however, not to healthy control levels $(\mathrm{P}<0.01)$. Upregulation of MMP-9 protein expression was significantly positively correlated with bronchial wall thickness ( $\mathrm{r}=0.887, \mathrm{P}<0.01$; Fig. 4G).

ERK and p-ERK expression. p-ERK level in lung tissues was detected by immunohistochemical staining. p-ERK was primarily located in the nucleus and cytoplasm of inflammatory and epithelial cells, as indicated in Fig. 5A-C.
p-ERK immunohistochemical staining was quantified using ImageJ. The p-ERK level was low in the control group; however, p-ERK was significantly increased in asthmatic mice $(66.79 \pm 15.7$ and $31.04 \pm 9.39 \%$, respectively; $\mathrm{P}<0.01)$. Administration of budesonide significantly reduced the p-ERK level $(52.38 \pm 10.42 \%)$ compared with the model group $(\mathrm{P}<0.05 ; \mathrm{P}=0.015)$, but did not entirely reduce the level of p-ERK to healthy control levels $(52.38 \pm 10.42$ and $31.04 \pm 9.39 \%$, respectively; $\mathrm{P}<0.01$; Fig. 5D). Western blotting confirmed that while the expression level of ERK did not differ between the groups, the level of p-ERK protein was higher in asthmatic mice $(\mathrm{P}<0.01)$, and significantly reduced by administration of budesonide $(\mathrm{P}<0.01$; Fig. 5E). p-ERK levels, measured using western blotting, were also significantly positively correlated with bronchial wall thickness $(\mathrm{r}=0.813, \mathrm{P}<0.01$; Fig. $5 \mathrm{~F})$. 

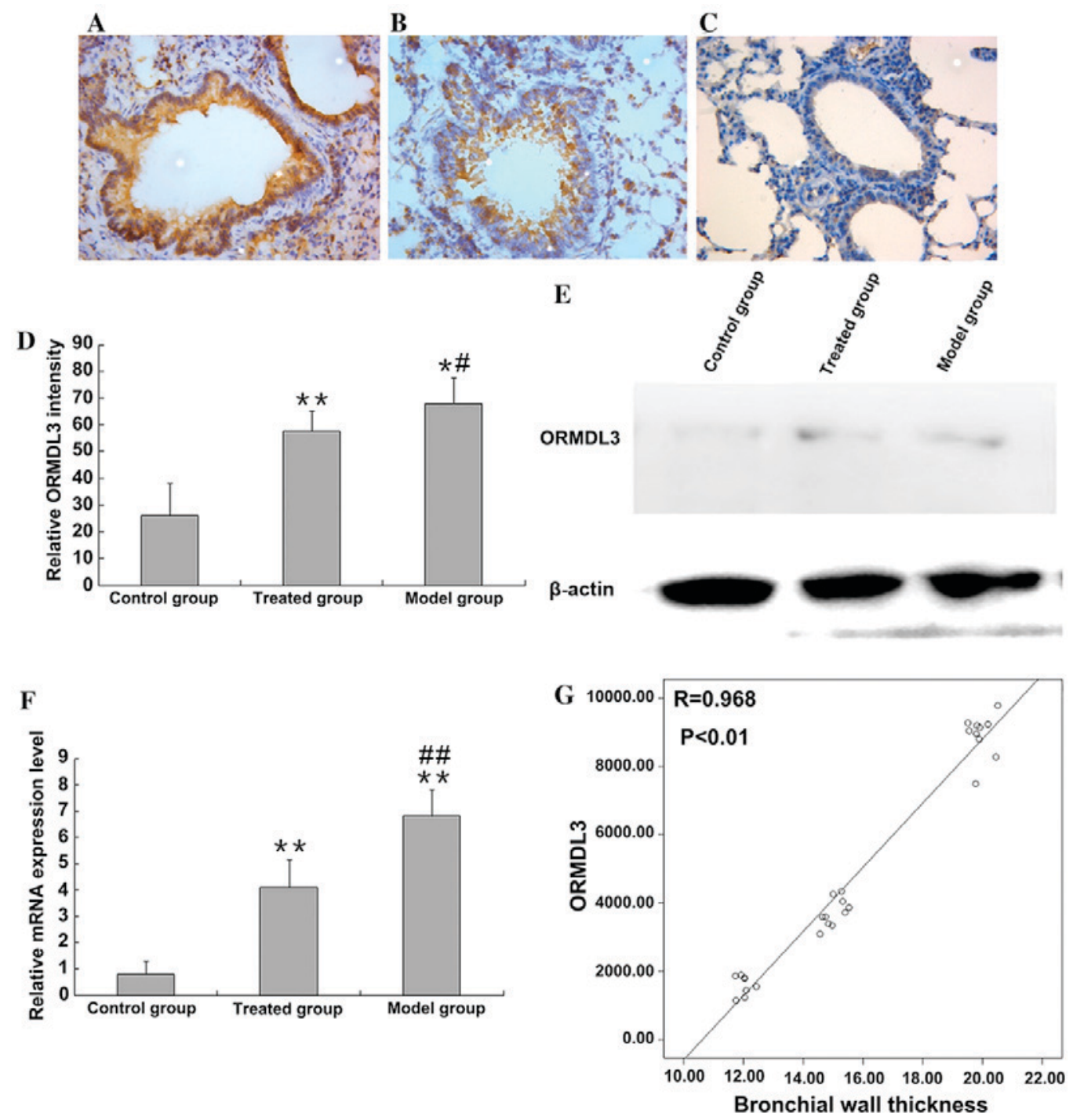

Figure 3. Expression levels of ORMDL3 protein in lung tissues of the (A) asthmatic model (B) budesonide-treated and (C) healthy control groups was investigated using immunohistochemistry. Magnification, x100. ORMDL3 protein expression was quantified using (D) ImageJ analysis of stained sections and (E) western blotting. (F) mRNA expression level of ORMDL3 in lung tissues was determined using reverse transcription-quantitative polymerase chain reaction. (G) ORMDL3 protein expression was positively correlated with bronchial wall thickness, $\mathrm{r}=0.968, \mathrm{P}<0.01$. ${ }^{*} \mathrm{P}<0.05$ and ${ }^{* *} \mathrm{P}<0.01$ vs. control; ${ }^{*} \mathrm{P}<0.05$ and ${ }^{\# \#} \mathrm{P}<0.01$ vs. treated. ORMDL3, orosomucoid-like 3.

Correlation between ORMDL3, MMP-9 and p-ERK levels. Correlational analysis was performed according to the results of western blotting. The present study determined that protein levels of ORMDL 3 were significantly positively associated with p-ERK ( $\mathrm{r}=0.727$; $\mathrm{P}<0.01$; Fig. 5G) and MMP-9 ( $\mathrm{r}=0.914$, $\mathrm{P}<0.01$; Fig. $5 \mathrm{H})$.

\section{Discussion}

ORMDL3 was previously defined as a novel oncogene, that may contribute to airway remodeling (16). The current study determined that ORMDL3 was upregulated in the lung tissues of an asthma mouse model. ORMDL3 was primarily located in the nucleus and cytoplasm of inflammatory and epithelial cells. Expression of ORMDL3 occurred along with markers of airway remodeling and pathological signs of airway remodeling, including epithelial cell shedding, tube wall edema, smooth muscle hyperplasia, collagen deposition and inflammatory cell infiltration were observed.
Airway remodeling may be a secondary process occurring in response to a chronic inflammatory environment and involves increased proliferation of inflammatory cells, epithelial cells and cytokine release. These factors affect the airway structures and pulmonary functions $(11,17)$. The present study identified exacerbated airway modeling in the OVA-induced asthma model, which was reduced by the administration of budesonide.

In the asthma mouse model established in the present study the expression of ORMDL3, MMP-9 and p-ERK was positively associated bronchial wall thickness, an indicator of airway remodeling severity. ORMDL3 was previously reported to be associated with asthma $(18,19)$. Allergen challenge was reported to induce a 127 -fold increase in ORMDL3 mRNA expression in the bronchial epithelium of wild-type mice (20-24). Previous studies have also revealed that ORMDL3 increased expression of proteases, including MMP-9, which is also associated with asthma pathogenesis (25-30). MMP-9 is produced by epithelial and 
A
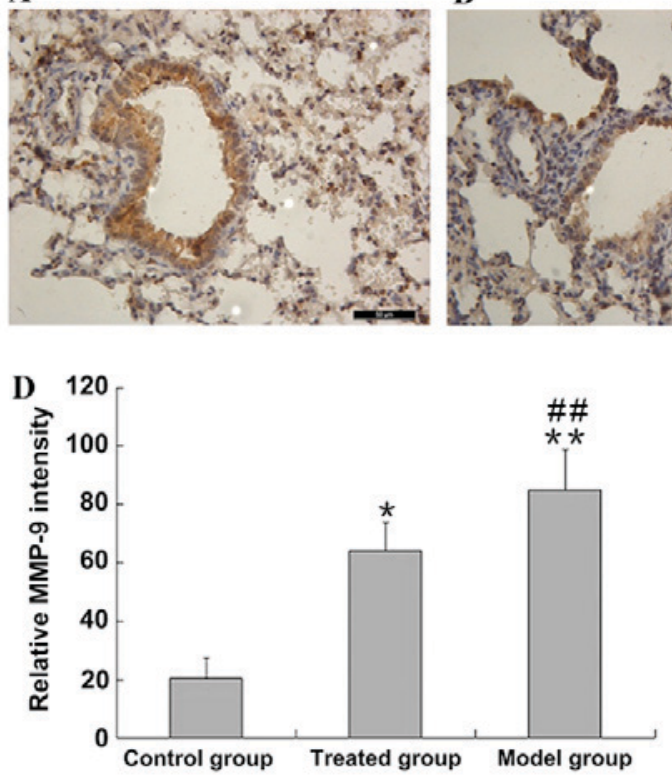

B

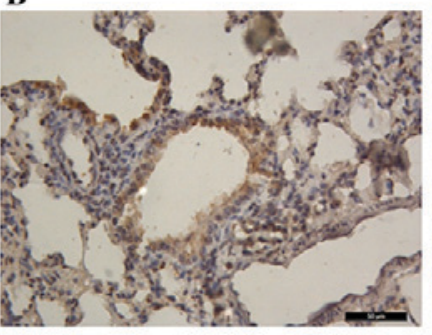

C

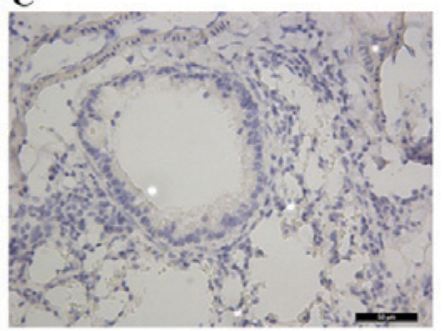

E

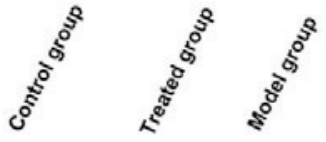

MMP-9

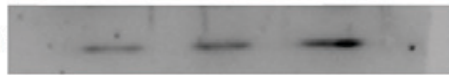

$\beta$-actin

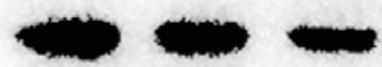

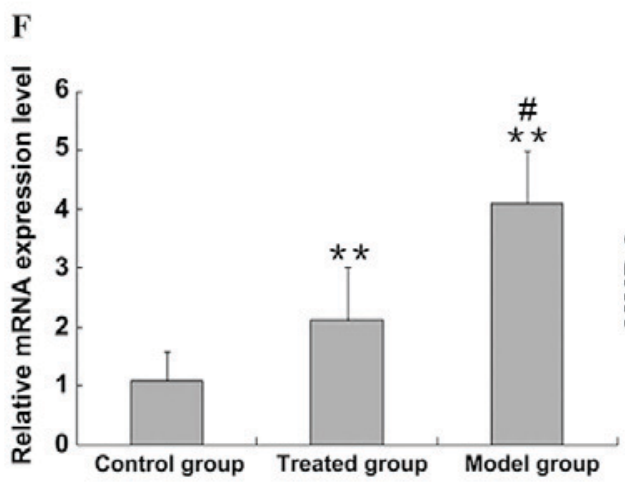

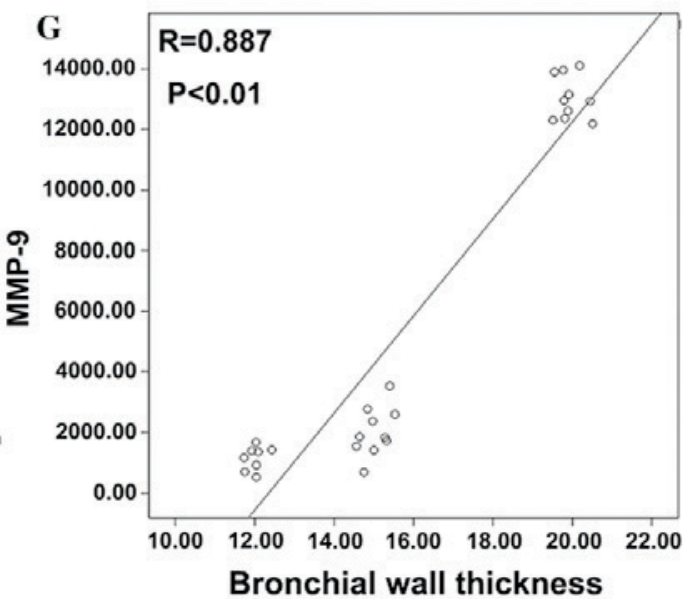

Figure 4. Expression levels of MMP-9 protein in lung tissues of the (A) asthmatic model (B) budesonide-treated and (C) healthy control groups was investigated using immunohistochemistry. Magnification, x100. MMP-9 protein expression was quantified (D) using ImageJ analysis of stained sections and (E) western blotting. (F) mRNA expression level of MMP-9 in lung tissues was determined using reverse transcription-quantitative polymerase chain reaction. (G) MMP-9 protein expression was positively correlated with bronchial wall thickness, $\mathrm{r}=0.887, \mathrm{P}<0.01$. ${ }^{*} \mathrm{P}<0.05$ and ${ }^{* *} \mathrm{P}<0.01$ vs. control; ${ }^{\#} \mathrm{P}<0.05$ and ${ }^{\# \#} \mathrm{P}<0.01$ vs. treated MMP-9, matrix metalloproteinase 9 .

inflammatory cells and upregulates release of matrix-associated growth factors, including transforming growth factor- $\beta 1$, leading to the degradation of collagen and thus induces infiltration of inflammatory cells through the basement membrane and ECM, accelerating collagen deposition. Therefore, these processes induce airway remodeling $(31,32)$. Thus, our observation that ORMDL3, MMP-9 and p-ERK expression were positively associated with bronchial wall thickness was consistent with previous studies.

In the present study ORMDL3 expression was also positively associated with levels of MMP-9 and p-ERK; therefore, ORMDL3 may induce the activation of MMP-9, and ORMDL3 may promote airway remodeling through the ERK/MMP-9 pathway. Previous studies of ORMDL3 expression in HEK 293 cells suggested that the primary impact of ORMDL3 expression is on the p-ERK/ERK pathway $(14,33)$. The ERK1/2 signaling pathway may stimulate extracellular signal transduction from the cell to the nucleus, through phosphorylation of transcription factors that regulate the activation of nuclear factor- $\mathrm{\kappa B}$, ETS protooncogene 1 and other transcription factors, thereby regulating the transcription of target genes, such as MMP-9 (34). Activation of the ROS-ERK-MMP-9 pathway may induce metastasis (35).

Administration of budesonide ameliorated airway remodeling in the OVA-induced asthma model and reduced the expression levels of ORMDL3, MMP-9 and p-ERK, indicating that budesonide may reduce airway remodeling by inhibiting the ORMDL3/ERK/MMP-9 pathway.

In conclusion, the findings of the present study suggest that ORMDL3 may induce MMP-9 expression in asthmatic mice via the ERK pathway, by inducing airway remodeling and that budesonide may alleviate bronchial hyperplasia and collagen deposition through the ORMDL3/ERK/MMP-9 pathway. However, the association between ORMDL3 and the ERK/MMP-9 pathway remains to be determined. Future 

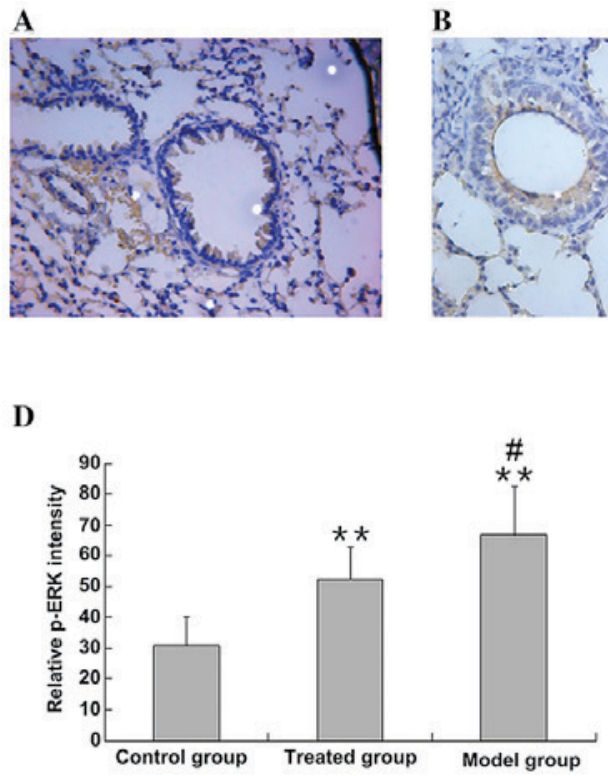

F

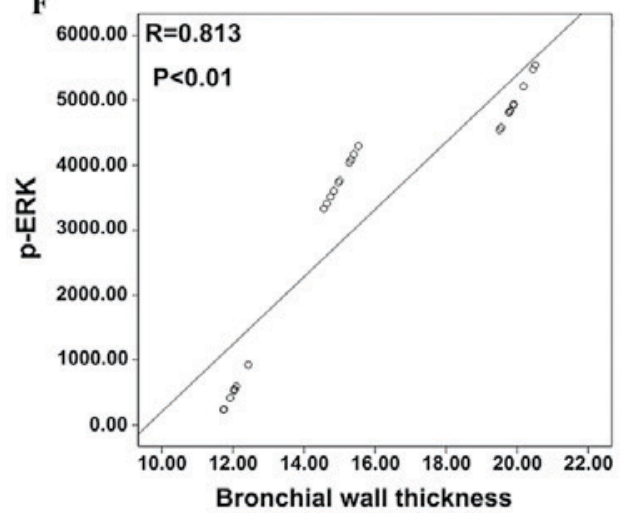

B

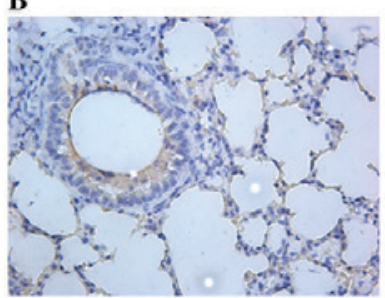

C

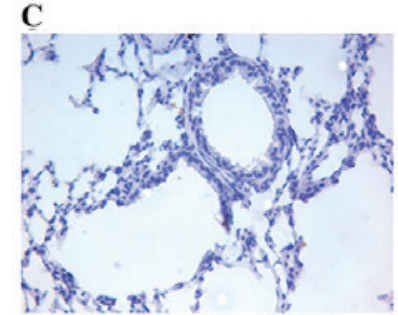

E

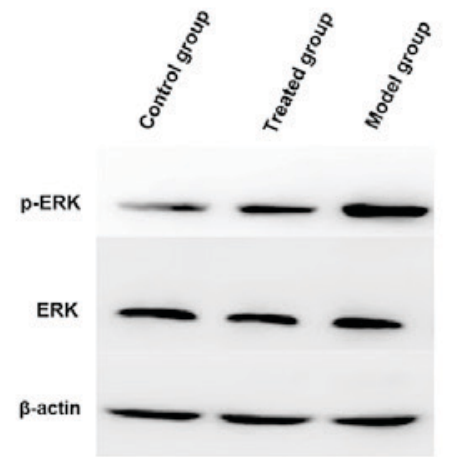

G

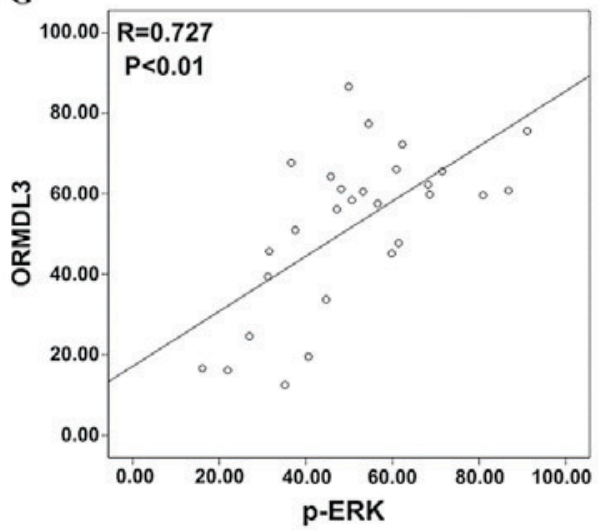

H

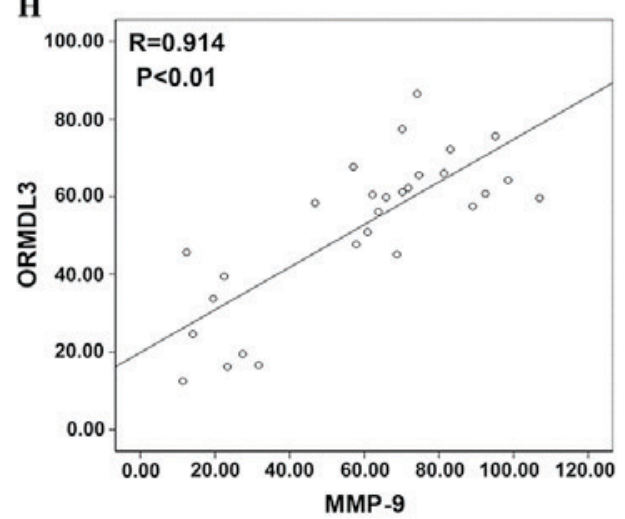

Figure 5. Expression levels of p-ERK protein in lung tissues of the (A) asthmatic model (B) budesonide-treated and (C) healthy control groups were investigated using immunohistochemistry. Magnification, x100. (D) p-ERK protein expression was quantified using ImageJ analysis of stained sections and (E) western blotting. RNA expression level of MMP-9 in lung tissues was determined using reverse transcription-quantitative polymerase chain reaction. ${ }^{* *} \mathrm{P}<0.01$ vs. control; ${ }^{\prime} \mathrm{P}<0.05$ vs. treated. (F) $p$-ERK protein expression was positively associated with bronchial wall thickness ( $\left.\mathrm{r}=0.813, \mathrm{P}<0.01\right)$ and $(\mathrm{G})$ ORMDL3 protein expression was positively associated with $\mathrm{p}$-ERK level $(\mathrm{r}=0.727, \mathrm{P}<0.01)$. (H) MMP-9 protein expression was positively associated with ORMDL3 expression level $(\mathrm{r}=0.914, \mathrm{P}<0.01)$. p-ERK, phosphorylated-extracellular-signal regulated kinase; ORMDL3, orosomucoid-like 3; MMP-9, matrix metalloproteinase 9.

investigations should identify the effects of ORMDL3 on the ROS-ERK/MMP-9 pathway using in vitro experiments and ORMDL3-knockout mice. Further understanding of the mechanisms responsible for pathological remodeling in asthma may highlight novel therapeutic strategies.

\section{Acknowledgements}

The authors would like to thank Dr Ningjiao at Traditional Chinese Hospital (Zibo, China) for proofreading of the manuscript. The present study was supported primarily by 
the Shandong Provincial Natural Science Foundation (grant no. ZR2013HQ034) and partly by the National Natural Science Foundation of China (grant no. 81500020).

\section{References}

1. Liu YN, Zha WJ, Ma Y, Chen FF, Zhu W, Ge A, Zeng XN and Huang M: Galangin attenuates airway remodelling by inhibiting TGF- $\beta 1$-mediated ROS generation and MAPK/Akt phosphorylation in asthma. Sci Rep 5: 11758, 2015.

2. Miller M, Rosenthal P, Beppu A, Mueller JL, Hoffman HM, Tam AB, Doherty TA, McGeough MD, Pena CA, Suzukawa M, et al: ORMDL3 transgenic mice have increased airway remodeling and airway responsiveness characteristic of asthma. J Immunol 192: 3475-3487, 2014.

3. Sun Y, Wang J, Li H, Sun L, Wang Y and Han X: The effects of budesonide on angiogenesis in a murine asthma model. Arch Med Sci 9: 361-367, 2013.

4. Jin R, Xu HG, Yuan WX, Zhuang LL, Liu LF, Jiang L, Zhu LH, Liu JY and Zhou GP: Mechanisms elevating ORMDL3 expression in recurrent wheeze patients: Role of Ets-1, p300 and CREB Int J Biochem Cell Biol 44: 1174-1183, 2012.

5. Hrdlickova B and Holla LI: Relationship between the 17q21 locus and adult asthma in a Czech population. Hum Immunol 72: 921-925, 2011

6. Moffatt MF, Kabesch M, Liang L, Dixon AL, Strachan D, Heath S, Depner M, von Berg A, Bufe A, Rietschel E, et al: Genetic variants regulating ORMDL3 expression contribute to the risk of childhood asthma. Nature 448: 470-473, 2007.

7. Hirota T, Harada M, Sakashita M, Doi S, Miyatake A, Fujita K, Enomoto T, Ebisawa M, Yoshihara S, Noguchi E, et al: Genetic polymorphism regulating ORM1-like 3 (Saccharomyces cerevisiae) expression is associated with childhood atopic asthma in a Japanese population. J Allergy Clin Immunol 121: 769-770, 2008.

8. Miller M, Tam AB, Cho JY, Doherty TA, Pham A, Khorram N, Rosenthal P, Mueller JL, Hoffman HM, Suzukawa M, et al: ORMDL3 is an inducible lung epithelial gene regulating metalloproteases, chemokines, OAS, and ATF6. Proc Natl Acad Sci USA 109: 16648-16653, 2012.

9. Kim SJ, Kim CH, Ahn JH, Kim MS, Kim SC, Lee SY, Kwon SS, Kim YK, Kim KH, Moon HS, et al: Time sequence of airway remodeling in a mouse model of chronic asthma: The relation with airway hyperresponsiveness. J Korean Med Sci 22: 183-191, 2007.

10. Schönbeck U, Mach F and Libby P: Generation of biologically active IL-1 beta by matrix metalloproteinases: A novel caspase-1-independent pathway of IL-1 beta processing. J Immunol 161: 3340-3346, 1998.

11. Felsen CN, Savariar EN, Whitney M and Tsien RY: Detection and monitoring of localized matrix metalloproteinase upregulation in a murine model of asthma. Am J Physiol Lung Cell Mol Physiol 306: L764-L774, 2014.

12. Lan YY, Hsiao JR, Chang KC, Chang JS, Chen CW, Lai HC, Wu SY, Yeh TH, Chang FH, Lin WH, et al: Epstein-Barr virus latent membrane protein $2 \mathrm{~A}$ promotes invasion of nasopharyngeal carcinoma cells through ERK/Fra-1-mediated induction of matrix metalloproteinase 9. J Virol 86: 6656-6667, 2012.

13. Ma HP, Li W and Liu XM: Matrix metalloproteinase 9 is involved in airway inflammation in cough variant asthma. Exp Ther Med 8: 1197-1200, 2014.

14. Sands MF: Localization of matrix metalloproteinase (MMP)-9 in lung tissue of a murine model of allergic asthma. Immunol Invest 41: 87-96, 2012.

15. Gueders MM, Foidart JM, Noel A and Cataldo DD: Matrix metalloproteinases (MMPs) and tissue inhibitors of MMPs in the respiratory tract: Potential implications in asthma and other lung diseases. Eur J Pharmacol 533: 133-144, 2006.

16. Van den Steen PE, Proost P, Wuyts A, Van Damme J and Opdenakker G: Neutrophil gelatinase B potentiates interleukin-8 tenfold by aminoterminal processing, whereas it degrades CTAP-III, PF-4 and GRO-alpha and leaves RANTES and MCP-2 intact. Blood 96: 2673-2681, 2000.
17. Hsu CH, Hu CM, Lu KH, Yang SF, Tsai CH, Ko CL, Sun HL and Lue KH: Effect of selective cysteinyl leukotriene receptor antagonists on airway inflammation and matrix metalloproteinase expression in a mouse asthma model. Pediatr Neonatol 53: 235-244, 2012.

18. Ferreira MA, McRae AF, Medland SE, Nyholt DR, Gordon SD, Wright MJ, Henders AK, Madden PA, Visscher PM, Wray NR, et al: Association between ORMDL3, IL1RL1 and a deletion on chromosome 17q21 with asthma risk in Australia. Eur J Hum Genet 19: 458-464, 2011.

19. Yang FF, Huang Y, Li QB, Dai JH and Fu Z: Single nucleotide polymorphisms in the ORM1-like 3 gene associated with childhood asthma in a Chinese population. Genet Mol Res 11: 4646-4653, 2012.

20. Galanter J, Choudhry S, Eng C, Nazario S, Rodríguez-Santana JR, Casal J, Torres-Palacios A, Salas J, Chapela R, Watson HG, et al: ORMDL 3 gene is associated with asthma in three ethnically diverse populations. Am J Respir Crit Care Med 177: 1194-1200, 2008.

21. Murray LA, Argentieri RL, Farrell FX, Bracht M, Sheng H, Whitaker B, Beck H, Tsui P, Cochlin K, Evanoff HL, et al: Hyper-responsiveness of IPF/UIP fibroblasts: Interplay between TGFbeta1, IL-13 and CCL2. Int J Biochem Cell Biol 40: 2174-2182, 2008

22. Zhao CN, Fan Y, Huang JJ, Zhang HX, Gao T, Wang C, Wang T and Hou LF: The association of GSDMB and ORMDL3 gene polymorphisms with asthma: A meta-analysis. Allergy Asthma Immunol Res 7: 175-185, 2015.

23. Nakamura Y, Esnault S, Maeda T, Kelly EA, Malter JS and Jarjour NN: Ets-1 regulates TNF-alpha-induced matrix metalloproteinase-9 and tenascin expression in primary bronchial fibroblasts. J Immunol 172: 1945-1952, 2004.

24. Wong KK: Recent developments in anti-cancer agents targeting the Ras/Raf/MEK/ERK pathway. Recent Pat Anticancer Drug Discov 4: 28-35, 2009.

25. Ha SG, Ge XN, Bahaie NS, Kang BN, Rao A, Rao SP and Sriramarao P: ORMDL3 promotes eosinophil trafficking and activation via regulation of integrins and CD48. Nat Commun 4: 2479, 2013.

26. Cataldo D, Munaut C, Noël A, Frankenne F, Bartsch P, Foidart JM and Louis R: MMP-2- and MMP-9-linked gelatinolytic activity in the sputum from patients with asthma and chronic obstructive pulmonary disease. Int Arch Allergy Immunol 123: 259-267, 2000.

27. Kavalar MS, Balantic M, Silar M, Kosnik M, Korosec P and Rijavec M: Association of ORMDL3, STAT6 and TBXA2R gene polymorphisms with asthma. Int J Immunogenet 39: 20-25, 2012.

28. Tian Y, Guan Y, Jia Y, Meng Q and Yang J: Chloride intracellular channel 1 regulates prostate cancer cell proliferation and migration through the MAPK/ERK pathway. Cancer Biother Radiopharm 29: 339-344, 2014.

29. Kelley J, Kovacs EJ, Nicholson K and Fabisiak JP: Transforming growth factor-beta production by lung macrophages and fibroblasts. Chest 99 (3 Suppl): 85S-86S, 1991.

30. Shifren A, Witt C, Christie C and Castro M: Mechanisms of remodeling in asthmatic airways. J Allergy (Cairo) 2012: 316049, 2012.

31. Ameredes BT, Zamora R, Gibson KF, Billiar TR, Dixon-McCarthy B, Watkins S and Calhoun WJ: Increased nitric oxide production by airway cells of sensitized and challenged IL-10 knockout mice. J Leukoc Biol 70: 730-736, 2001.

32. Liu $P$ and Wilson MJ: miR-520c and miR-373 upregulate MMP9 expression by targeting mTOR and SIRT1 and activate the Ras/Raf/MEK/Erk signaling pathway and NF- $\mathrm{BB}$ factor in human fibrosarcoma cells. J Cell Physiol 227: 867-876, 2012.

33. Cantero-Recasens G, Fandos C, Rubio-Moscardo F, Valverde MA and Vicente R: The asthma-associated ORMDL3 gene product regulates endoplasmic reticulum-mediated calcium signaling and cellular stress. Hum Mol Genet 19: 111-121, 2010.

34. Bergeron C, Tulic MK and Hamid Q: Airway remodelling in asthma: From benchside to clinical practice. Can Respir J 17: e85-e93, 2010.

35. Montagut $\mathrm{C}$ and Settleman J: Targeting the RAF-MEK-ERK pathway in cancer therapy. Cancer Lett 283: 125-134, 2009. 